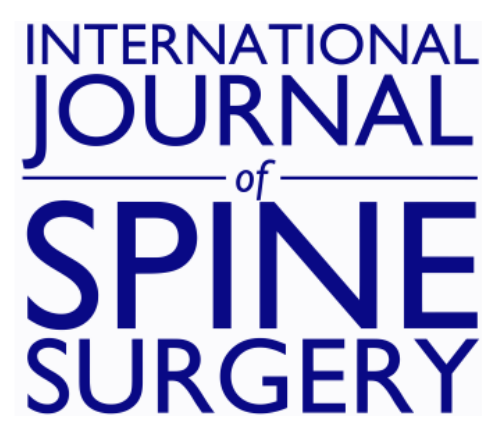

\title{
Can Imaging Characteristics on Magnetic Resonance Imaging Predict the Acuity of a Lumbar Disc Herniation?
}

Srikanth N. Divi, Dhruv K.C. Goyal, Heeren S. Makanji, Christopher K. Kepler, D. Greg Anderson, Eric D. Warner, Matthew S. Galetta, Victor E. Mujica, Nathan V. Houlihan, I. David Kaye, Mark F. Kurd, Barrett I. Woods, Kris E. Radcliff, Jeffrey A. Rihn, Alan S. Hilibrand, Alexander R. Vaccaro and Gregory D. Schroeder

Int J Spine Surg 2021, 15 (3) 458-465

doi: https://doi.org/10.14444/8032

http://ijssurgery.com/content/15/3/458

This information is current as of April 26, 2023.

Email Alerts Receive free email-alerts when new articles cite this article. Sign up at:

http://ijssurgery.com/alerts

The International Journal of Spine Surgery

2397 Waterbury Circle, Suite 1,

Aurora, IL 60504, Phone: +1-630-375-1432 


\title{
Can Imaging Characteristics on Magnetic Resonance Imaging Predict the Acuity of a Lumbar Disc Herniation?
}

SRIKANTH N. DIVI, MD, DHRUV K.C. GOYAL, MD, HEEREN S. MAKANJI, MD, CHRISTOPHER K. KEPLER, MD, MBA, D. GREG ANDERSON, MD, ERIC D. WARNER, BS, MATTHEW S. GALETTA, BA, VICTOR E. MUJICA, MD, NATHAN V. HOULIHAN, BS, I. DAVID KAYE, MD, MARK F. KURD, MD, BARRETT I. WOODS, MD, KRIS E. RADCLIFF, MD, JEFFREY A. RIHN, MD, ALAN S. HILIBRAND, MD, ALEXANDER R. VACCARO, MD, PHD, MBA, GREGORY D. SCHROEDER, MD

Department of Orthopaedic Surgery, Rothman Institute, Thomas Jefferson University, Philadelphia, Pennsylvania

\begin{abstract}
Background: Currently, no authors of existing studies have attempted to classify the signal characteristics of disc herniation on magnetic resonance imaging (MRI) and their temporal relationship to symptoms of lumbar radiculopathy. The purpose of this study was to determine whether the MRI signal characteristics are predictive of acuity of symptoms in patients with lumbar disc herniation (LDH).

Methods: A retrospective cohort study was conducted on patients treated at an academic center for LDH from 2015 to 2018. Patients were divided into 2 groups based on symptom duration (acute: $\leq 6$ weeks; or chronic: $>4$ months). Two independent observers measured T1, T2 signal, and other MRI characteristics at the affected disc level. Univariate analysis was used to compare differences between groups. Multiple logistic regression was used to determine predictors of acuity.

Results: Eighty-nine patients were included (33 acute, 56 chronic) with no significant baseline differences between groups. Rater 2 observed a higher proportion of disc bulges in the chronic group $(P=.021)$ and a higher abnormal T1 herniation signal in the acute group $(P=.048)$. Rater 1 found a higher Pfirrmann grade $(P=.005)$ and a higher prevalence of vertebral body spurring $(P=.007)$ in the chronic group. Interobserver agreement for T1 central and herniation signals demonstrated poor to fair agreement, whereas the remainder of the measurements showed moderate to substantial agreement $(\kappa=0.4-0.8)$. Multiple logistic regression showed that Pfirrmann Grade 5 (odds ratio $=0.12$, $95 \%$ confidence interval $[0.02,0.74], P=.022$ ) and anterior/posterior spurring (odds ratio $=0.053[0.03,0.85], P=.023$ ) were not associated with acuity.
\end{abstract}

Conclusions: Other than Pfirrmann grade or vertebral body spurring, no MRI characteristics could be reliably identified that correlate with acuity of symptoms.

Level of Evidence: 3 .

Lumbar Spine

Keywords: radiculopathy, T1 central, T2 central, T1 herniation, T2 herniation, Pfirrmann grade

\section{INTRODUCTION}

Lumbar disc herniation ( $\mathrm{LDH})$ is the most common cause of lower extremity radiculopathy. ${ }^{1}$ Patients may initially present to the treating physician with symptoms lasting from days to months or even years and varying degrees of disability. Magnetic resonance imaging (MRI) is the imaging modality of choice, given its relatively high sensitivity $(75 \%)$ compared with computed tomography. ${ }^{2}$ However, authors of several studies have shown that MRI may lack specificity due to the high prevalence of abnormal anatomical findings among asymptomatic patients. ${ }^{3-5}$ Therefore, a causal association between clinical symptoms and diagnostic imaging findings is necessary for an accurate diagnosis.

In initial controlled prospective studies conducted on patients with lower extremity radiculopathy due to disc herniation, Weber ${ }^{6}$ and Weber et $\mathrm{al}^{7}$ suggest that approximately $70 \%$ of patients gain functional improvement with conservative therapy, and $60 \%$ of patients are able to return to work, with only $20 \%$ of patients experiencing recurrence of radiculopathy. As a result, given the high incidence of LDH in the asymptomatic population, pinpointing the acuity of a disc herniation in a patient can be difficult. $^{3}$ In addition, spontaneous regression of LDH is a common and recognized phenomenon. ${ }^{8,9}$ 
In 1 systematic review including 31 studies, the rate of spontaneous regression was $13 \%$ for bulging, $41 \%$ for protrusion, $70 \%$ for extrusion, and $96 \%$ for sequestration. ${ }^{10}$ While the exact mechanisms behind this process are still unknown, they may explain the resolution of symptoms in patients undergoing conservative treatment. Rim enhancement surrounding herniated discs on contrastenhanced MRIs are thought to represent vascular granulation tissue and thus may be indicative of the potential for these herniations to resorb spontaneously. ${ }^{8}$ Authors of some studies have attempted to classify the size and location of disc herniations to correlate with patient symptoms. ${ }^{1-14}$ Other investigators have noted the presence of a high-intensity zone in patients with low back pain, which is described as a high-intensity signal on T2-weighted MRI sequences and is located in the posterior annulus fibrosus, clearly separating it from the nucleus pulposus. ${ }^{15}$ While controversial, these lesions are thought to represent internal disc disruption and annular tears resulting in low back pain. However, these findings are not directly relatable to determining the acuity of a disc herniation.

To date, no authors have attempted to classify the signal characteristics of the disc herniation on MRI and their temporal relationship to symptoms of lumbar radiculopathy. The purpose of this study is to determine whether specific characteristics on T1- or T2-weighted MRI sequences are predictive of acuity of symptoms.

\section{MATERIALS AND METHODS}

This study was approved by the Institutional Review Board at the Thomas Jefferson University Hospital. Each author certifies that his or her institution approved the human protocol for this investigation and that all investigations were conducted in conformity with ethical principles of research. After institutional review board approval, patients being treated at a single, high-volume academic institution with a diagnosis of LDH by 1 of 10 fellowship-trained orthopaedic spine surgeons between January 1st, 2015, and August 30th, 2018, were retrospectively identified. Only patients over the age of 18 and those with available MRI in the institution's picture archiving and communication system (PACS) were included in the analysis. Demographic data for all patients were collected. Clinic notes were reviewed to determine the duration of symptoms for each patient upon

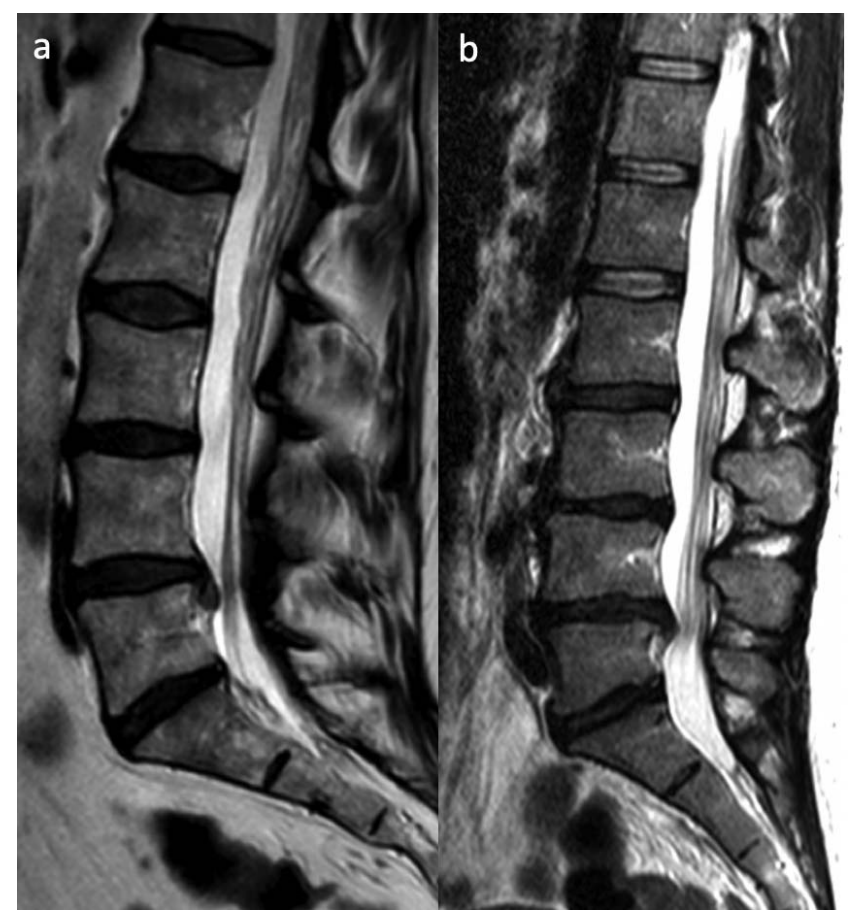

Figure 1. Disc Height. (a) Example normal disc height with herniation at L4-5. (b) Example of decreased disc height with herniation at L4-5.

presentation to the treating spine surgeon. The period from the onset of symptoms to the first date that an MRI was ordered was noted. Patients were then divided into 2 groups based on time to MRI: acute ( $\leq 6$ weeks) or chronic ( $>4$ months). In addition, the rate of operative intervention was calculated. The time to surgery (months) was recorded as the time from first presentation to the treating surgeon to surgery, regardless of when the patient first began to experience symptoms.

All imaging characteristics evaluated were assessed from MRI using the institution's PACS system: Sectra Workstation IDS7 18.2 (Sectra AB; Linköping, Sweden). MRI characteristics specific to the disc space that were assessed included type of herniation (bulge, protrusion, extrusion, and sequestration), disc height, T2 central signal, T2 herniation signal, T1 central signal, T1 herniation signal, and Pfirrmann grade. These characteristics were individually graded by 2 orthopaedic spine fellows (Rater 1 and Rater 2). Specifically, these characteristics were graded as either normal or abnormal and assessed on both sagittal and axial sequences. Disc characteristics were graded using the following criteria as previously described by Milette et al. ${ }^{16}$ Disc height was graded as normal if the height was equal to or greater than the next unaffected cranial disc (Figure 1). The central aspect 


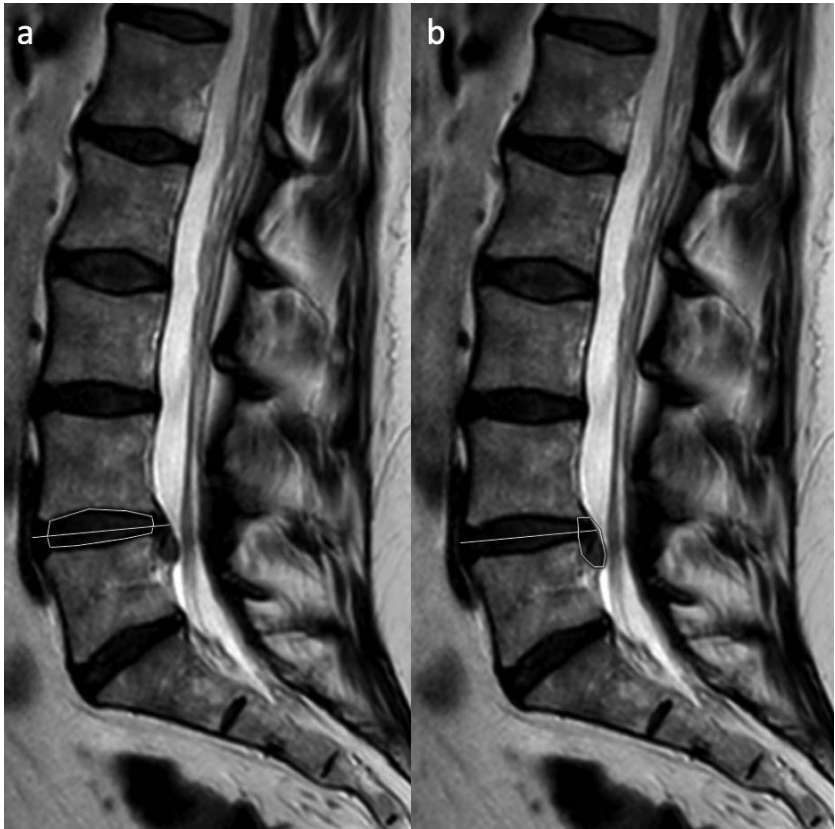

Figure 2. Area of measurement of (a) T2 central and (b) T2 herniation signal on sagittal $\mathrm{T} 2$ sequence.

of the intervertebral disc was designated as the inner $80 \%$, and the herniation aspect of the disc was designated as the outer $20 \%$. Abnormal T2 central signal was graded as either an increase or decrease in signal compared with the cranial-most unaffected disc (usually T11-12, T12-L1, or L1-2). Grading of central intensity was further classified using the Pfirrmann classification. ${ }^{17}$ Abnormal T2 herniation signal was graded as abnormal if an increase in signal was detected. Abnormal T1 signal was a decrease (darkening) relative to the cranial-most disc. Examples of measurements are shown in Figures 2 and 3. Other MRI characteristics known to be associated with disc herniations were also reviewed: presence of nerve root compression, endplate (Modic) changes, presence of facet degeneration, vertebral body spurring (anterior, posterior, or anterior and posterior), and ligamentum flavum hypertrophy $(>5.0 \mathrm{~mm})$. Figure 4 depicts measurement of ligamentum flavum thickness, and Figure 5 depicts a patient with concomitant anterior spurring and Type 2 Modic changes. All these latter characteristics were measured by only Rater 1 .

\section{Statistical Analysis}

Continuous data between groups were compared using Student's $t$ test, and categorical data were compared using Pearson $\chi^{2}$ analysis or a Fisher's Exact test. Interobserver reliability comparing

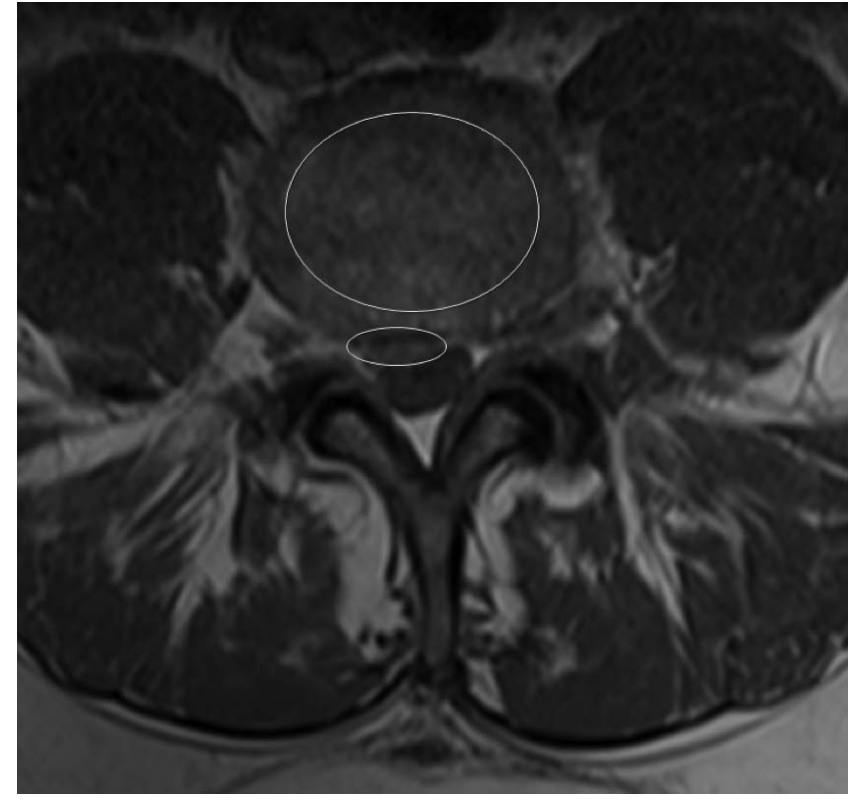

Figure 3. Measurement of $\mathrm{T} 1$ central signal and $\mathrm{T} 1$ herniation signal on axial T1 sequence.

measurements between Rater 1 and Rater 2 was performed by calculating the Fleiss $\kappa$ statistic. $^{18}$ Strength of agreement was interpreted using the Landis and Koch grading system ( $<0$ is poor, $0.01-$ 0.20 is slight, $0.21-0.40$ is fair, $0.41-0.60$ is moderate, $0.61-0.80$ is substantial, and $0.81-1.00$ is almost perfect). ${ }^{19}$ Multiple logistic regression analysis controlling for age, sex, and disc level was performed to determine the odds of each MRI

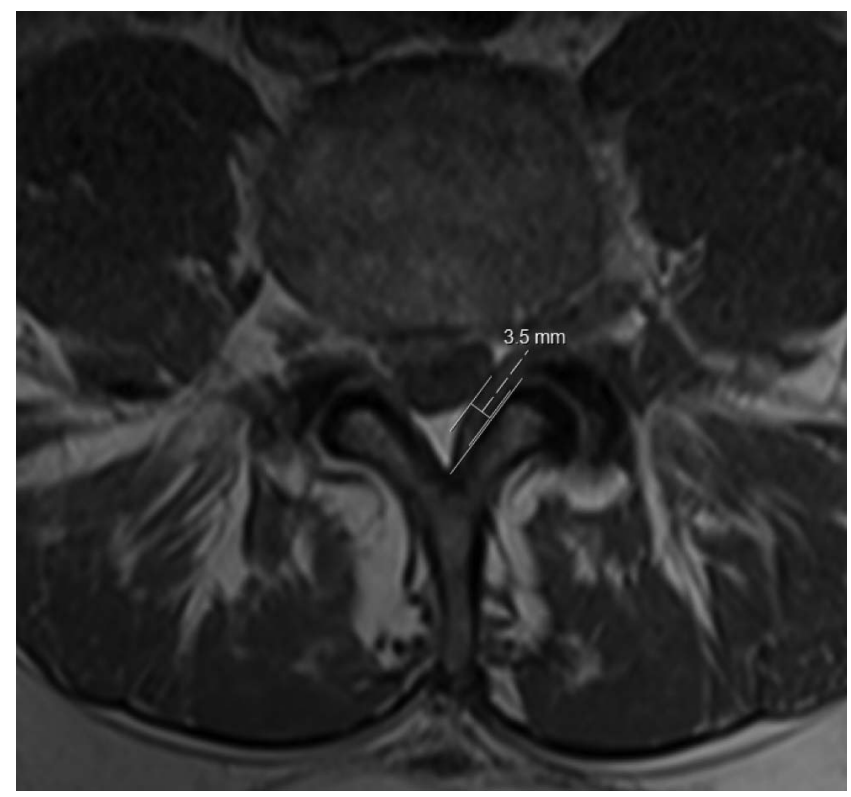

Figure 4. Measurement of ligamentum flavum thickness at the midpoint along interior lamina. $>5.0 \mathrm{~mm}$ was considered indicative of ligamentum flavum hypertrophy. 


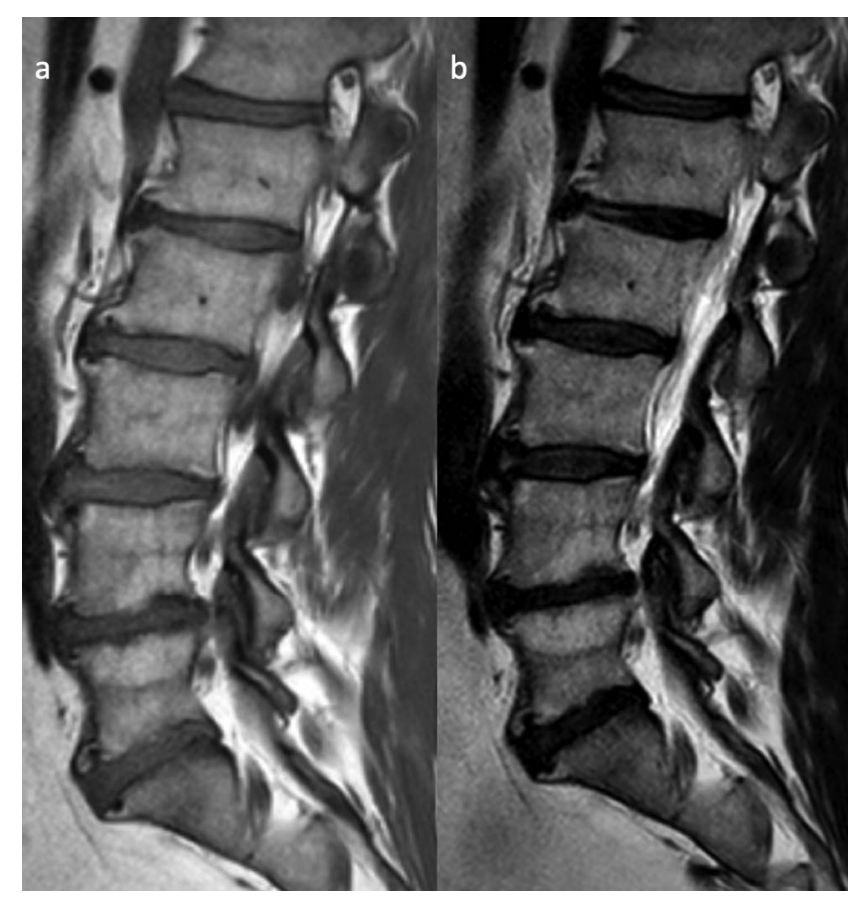

Figure 5. (a) Sagittal T1 and (b) sagittal T2 images depicting anterior vertebral body spurring and Type 2 Modic changes.

characteristic predicting acuity of symptoms $(<6$ weeks). All statistical analyses were performed using SPSS, version 24 (IBM Corporation, Armonk, NY). A $P$ value of less than .05 for each test was considered statistically significant.

\section{RESULTS}

A total of 89 patients were included in the final analysis, with 33 patients in the acute symptoms group and 56 patients in the chronic symptoms group (Table 1). No difference in age between groups existed (acute: 49.2 years, 95\% confidence interval $[43.0,54.5]$ versus chronic: 50.2 years [46.4, 54.1], $P=.750)$. There was a total of $20(60.6 \%)$ males in the acute group and $28(50.0 \%)$ males in the chronic group $(P=.230)$. A total of 3 patients had disc herniations at the L1-2 level, 2 patients at the L2-3 level, 6 patients at the L3-4 level, 41 patients at the L4-5 level, and 37 patients at the L5S1 level. When comparing the type of disc herniation, a greater proportion of patients were noted to have disc protrusion in both the acute and chronic groups by both observers. When comparing type of herniation between groups, Rater 1 found no significant difference in the proportion of patients with each herniation type $(P=.155)$, whereas Rater 2 noted a significant difference between groups $(P=$ $.021)$ with a higher proportion of disc bulges and lower proportion of disc sequestrations in the chronic group. Interobserver reliability for this measurement was $\kappa=0.590$, indicating moderate agreement. A total of 20 patients $(60.6 \%)$ in the acute group and 35 patients in the chronic group $(62.5 \%)$ underwent surgery $(P=.859)$. No difference in the time from initial presentation to surgery between groups existed (2.35 months [1.27, 3.43] versus 2.24 months $[1.30,3.19] ; P=.563)$.

When comparing MRI characteristics of disc herniation, no significant differences between groups for either rater for disc height, T2 central signal, T2 herniation signal, or T1 herniation signal

Table 1. Baseline characteristics.

\begin{tabular}{|c|c|c|c|c|c|}
\hline Parameter & \multicolumn{2}{|c|}{ Acute, $\mathbf{n}=\mathbf{3 3}$} & \multicolumn{2}{|c|}{ Chronic, $n=56$} & $P$ Value \\
\hline Age, mean $[95 \% \mathrm{CI}]$, y & \multicolumn{2}{|c|}{$49.2[43.0,54.5]$} & \multicolumn{2}{|c|}{$50.2[46.4,54.1]$} & .750 \\
\hline Sex, n $(\%)$ & & & \multirow{2}{*}{\multicolumn{2}{|c|}{$28(50.0)$}} & \\
\hline Female & \multicolumn{2}{|c|}{$13(39.4)$} & & & .230 \\
\hline Male & \multicolumn{2}{|c|}{$20(60.6)$} & \multicolumn{2}{|c|}{$28(50.0)$} & \\
\hline \multicolumn{6}{|l|}{ Disc level, $\mathrm{n}(\%) \mathrm{l}$} \\
\hline L1-2 & \multicolumn{2}{|c|}{$0(0)$} & \multicolumn{2}{|c|}{$3(5.4)$} & .157 \\
\hline L2-3 & \multicolumn{2}{|c|}{$2(6.1)$} & \multicolumn{2}{|c|}{$0(0)$} & \\
\hline L3-4 & & & \multicolumn{2}{|c|}{$5(8.9)$} & \\
\hline L4-5 & \multicolumn{2}{|c|}{$17(51.5)$} & \multirow{2}{*}{\multicolumn{2}{|c|}{$\begin{array}{l}24(42.9) \\
24(42.9)\end{array}$}} & \\
\hline L5-S1 & \multicolumn{2}{|c|}{$13(39.4)$} & & & \\
\hline Type of herniation, $n(\%)$ & Rater 1 & Rater 2 & Rater 1 & Rater 2 & \\
\hline Bulge & $6(18.2)$ & $6(18.2)$ & $21(37.5)$ & $23(41.1)$ & .155 \\
\hline Protrusion & $19(57.6)$ & $15(45.5)$ & $29(51.8)$ & $24(42.9)$ & $.021^{\mathrm{a}}$ \\
\hline Extrusion & $6(18.2)$ & $9(27.3)$ & $5(8.9)$ & $9(16.1)$ & $\kappa=0.590$ \\
\hline Sequestration & $2(6.1)$ & $3(9.1)$ & $1(1.8)$ & $0(0)$ & \\
\hline \multicolumn{6}{|l|}{ Underwent surgery, n (\%) } \\
\hline No & \multirow{2}{*}{\multicolumn{2}{|c|}{$13(39.4)$}} & \multicolumn{2}{|c|}{$21(37.5)$} & .859 \\
\hline Yes & & & \multicolumn{2}{|c|}{$35(62.5)$} & \\
\hline Time to surgery, mean $[95 \% \mathrm{CI}]$, mo & \multicolumn{2}{|c|}{$2.35[1.27,3.43]$} & \multicolumn{2}{|c|}{$2.24[1.30,3.19]$} & .563 \\
\hline
\end{tabular}

Abbreviation: CI, confidence interval.

${ }^{\mathrm{a}}$ Value is statistically significant $(P<.05)$. 
Table 2. Magnetic resonance imaging characteristics of disc herniation.

\begin{tabular}{|c|c|c|c|c|c|}
\hline & \multicolumn{2}{|c|}{ Acute, $n=33, n(\%)$} & \multicolumn{2}{|c|}{ Chronic, $n=56, n(\%)$} & \multirow[b]{2}{*}{$P$ Value } \\
\hline & Rater 1 & Rater 2 & Rater 1 & Rater 2 & \\
\hline \multicolumn{6}{|l|}{ Disc height } \\
\hline Normal & $8(24.2)$ & $15(45.5)$ & $18(32.1)$ & $27(48.2)$ & .429 \\
\hline Decreased & $25(75.8)$ & $18(54.5)$ & $38(67.9)$ & $29(51.8)$ & $\begin{array}{c}.801 \\
\kappa=0.664\end{array}$ \\
\hline \multicolumn{6}{|c|}{$\mathrm{T} 2$ central signal } \\
\hline Normal & $0(0)$ & $0(0)$ & $4(7.1)$ & $2(3.6)$ & .292 \\
\hline Abnormal & $33(100.0)$ & $33(100.0)$ & $52(92.9)$ & $54(96.4)$ & $\begin{array}{c}.528 \\
\kappa=0.479\end{array}$ \\
\hline \multicolumn{6}{|c|}{$\mathrm{T} 2$ herniation signal } \\
\hline Normal & $19(54.3)$ & $21(63.6)$ & $34(60.7)$ & $35(62.5)$ & .545 \\
\hline Abnormal & $16(45.7)$ & $12(36.4)$ & $22(39.3)$ & $21(37.5)$ & $\begin{array}{c}.915 \\
\kappa=0.542\end{array}$ \\
\hline \multicolumn{6}{|c|}{$\mathrm{T} 1$ central signal } \\
\hline Normal & $31(93.9)$ & $30(90.9)$ & $52(92.9)$ & $56(100)$ & .844 \\
\hline Abnormal & $2(6.1)$ & $3(9.1)$ & $4(7.1)$ & $0(0)$ & $\begin{array}{c}.048^{\mathrm{a}} \\
\kappa=-0.100\end{array}$ \\
\hline \multicolumn{6}{|c|}{ T1 herniation signal } \\
\hline Normal & $21(63.6)$ & $17(51.5)$ & $31(55.4)$ & $39(69.6)$ & .444 \\
\hline Abnormal & $12(36.4)$ & $16(48.5)$ & $25(44.6)$ & $17(30.4)$ & $\begin{array}{c}.087 \\
\kappa=0.269\end{array}$ \\
\hline \multicolumn{6}{|c|}{ Pfirrmann grade } \\
\hline 2 & $0(0)$ & $6(18.2)$ & $0(0)$ & $13(23.2)$ & $.005^{\mathrm{a}}$ \\
\hline 3 & $8(24.2)$ & 19 (57.6) & $11(21.2)$ & $29(51.8)$ & .667 \\
\hline 4 & $23(69.7)$ & $8(24.2)$ & $22(42.3)$ & $10(17.9)$ & $\kappa=0.479$ \\
\hline 5 & $2(6.1)$ & $0(0)$ & $19(36.5)$ & $2(3.7)$ & \\
\hline
\end{tabular}

${ }^{\mathrm{a}}$ Value is statistically significant $(P<.05)$.

existed (Table 2). When comparing T1 central signal, a significant difference between groups for Rater $2(P=.048)$ with the acute group showed 3 patients with abnormal signal and none in the chronic group. However, this was not significant for Rater 1 and showed a reverse trend where 2 patients in the acute group and 4 patients in the chronic group were rated to have abnormal signal $(P=$ $.844)$. This was indicated by poor interobserver

Table 3. Other magnetic resonance imaging characteristics.

\begin{tabular}{lccc}
\hline & $\begin{array}{c}\text { Acute, } \\
\mathbf{n}=\mathbf{3 3}, \\
\mathbf{n}(\mathbf{\%})\end{array}$ & $\begin{array}{c}\text { Chronic, } \\
\mathbf{n}=\mathbf{5 6}, \\
\mathbf{n}(\mathbf{\%})\end{array}$ & $\boldsymbol{P}$ Value \\
\hline Nerve root compression & & & \\
0 & $8(24.2)$ & $17(30.4)$ & .535 \\
1 & $25(75.8)$ & $39(69.6)$ & \\
Modic changes & & & \\
Normal & $26(78.8)$ & $40(72.4)$ & .186 \\
Type 1 & $0(0)$ & $5(8.9)$ & \\
Type 2 & $6(18.2)$ & $11(19.6)$ & \\
Type 3 & $1(3.0)$ & $0(0)$ & \\
Facet degeneration & & & \\
Absent & $15(45.5)$ & $20(35.7)$ & .364 \\
Present & $18(54.5)$ & $36(64.3)$ & \\
Spurring & & & \\
None & $30(90.9)$ & $32(57.1)$ & $.007^{\mathrm{a}}$ \\
Anterior marginal & $2(6.1)$ & $7(12.5)$ & \\
Posterior marginal & $0(0)$ & $5(8.9)$ & \\
Anterior and posterior & $1(3.0)$ & $12(21.4)$ & \\
Ligamentum flavum Hypertrophy & & & \\
Absent & $30(90.9)$ & $46(82.1)$ & .357 \\
Present & $3(9.1)$ & $10(17.9)$ & \\
\hline
\end{tabular}

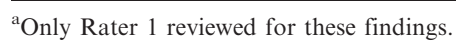

agreement $(\kappa=-0.100)$. When assessing Pfirrmann grade, a significant difference occurred between groups for Rater $1(P=.005)$, with the acute group having a higher proportion of Grade 4 discs. No difference occurred in Pfirrmann grade between groups for Rater $2(P=.667)$. Interobserver agreement was moderate $(\kappa=0.479)$.

The remainder of the MRI characteristics measured are shown in Tables 3 and 4 . No significant differences existed between acute and chronic groups with regard to the presence of nerve compression $(P=.535)$, endplate (Modic) changes $(P=.186)$, facet degeneration $(P=.364)$, or ligamentum flavum hypertrophy $(P=.357)$. Patients in the chronic group were noted to have a higher proportion of patients with anterior marginal, posterior marginal, and anterior and posterior vertebral body spurring $(P=.007)$. Results of the multiple logistic regression analysis showed that decreased disc height $(P=.532$ and .451 , for Rater 1 and 2 , respectively), type of herniation $(P=.226$ and $.283)$, abnormal T2 central $(P=.999$ and .999$)$, abnormal T2 herniation signal $(P=.525$ and .177$)$, abnormal $\mathrm{T} 1$ central signal $(P=.937$ and .999$)$, and abnormal $\mathrm{T} 1$ herniation signal $(P=.618$ and .353$)$ were not significant predictors of acuity of symptoms. For Rater 1, the presence of Pfirrmann Grade 5 indicated decreased odds of acuity of symptoms 
Divi et al.

Table 4. Multiple logistic regression. Odds of predicting acuity of symptoms, controlling for age, sex, and disc level.

\begin{tabular}{|c|c|c|c|c|c|c|}
\hline & \multicolumn{2}{|c|}{ Rater 1} & \multirow[b]{2}{*}{$P$} & \multicolumn{2}{|c|}{ Rater 2} & \multirow[b]{2}{*}{$\boldsymbol{P}$} \\
\hline & $\beta$ Coefficient & Odds Ratio $[95 \% \mathrm{CI}]$ & & $\beta$ Coefficient & Odds Ratio $[95 \% \mathrm{CI}]$ & \\
\hline Disc height & 0.338 & $1.40[0.49,4.06]$ & .532 & -0.390 & $0.68[0.25,1.87]$ & .451 \\
\hline Type of herniation & & & .226 & & & .283 \\
\hline Bulge & NA & NA & NA & NA & NA & NA \\
\hline Protrusion & 0.754 & $2.13[0.70,6.44]$ & .183 & 0.824 & $2.28[0.75,6.95]$ & .148 \\
\hline Extrusion & 1.351 & $3.86[0.81,18.4]$ & .090 & 1.278 & $3.59[0.96,13.4]$ & .058 \\
\hline Sequestration & 1.985 & $7.28[0.55,95.9]$ & .131 & 22.67 & NA & .999 \\
\hline Abnormal $\mathrm{T} 2$ central signal & 20.75 & NA & .999 & 19.9 & NA & .999 \\
\hline Abnormal T2 herniation signal & 0.294 & $1.34[0.54,3.32]$ & .525 & -0.804 & $0.45[0.14,1.44]$ & .177 \\
\hline Abnormal T1 central signal & 0.075 & $1.08[0.17,7.01]$ & .937 & 22.12 & NA & .999 \\
\hline Abnormal $\mathrm{T} 1$ herniation signal & -0.230 & $0.79[0.32,1.96]$ & .618 & 0.483 & $1.62[0.59,4.49]$ & .353 \\
\hline Pfirrmann grade & & & $.018^{\mathrm{a}}$ & & & \\
\hline 2 & & & & NA & NA & NA \\
\hline 3 & NA & NA & NA & 19.93 & NA & .999 \\
\hline 4 & 0.213 & $1.24[0.39,3.98]$ & .720 & 20.14 & NA & .999 \\
\hline 5 & -2.094 & $0.12[0.02,0.74]$ & $.022^{\mathrm{a}}$ & 20.02 & NA & .999 \\
\hline
\end{tabular}

Abbreviations: CI, confidence interval; NA, not applicable

${ }^{\mathrm{a}}$ Value is statistically significant $(P<.05)$.

(odds ratio $=0.12[0.02,0.74], P=.022$ ). Of the remaining MRI characteristics, only the presence of anterior and posterior spurring indicated decreased odds of acuity of symptoms (odds ratio $=0.053, P=$ $.023)$.

\section{DISCUSSION}

LDH is an extremely prevalent condition resulting in low back pain as well as lower extremity pain. Due to the often self-limited course of radiculopathy, many patients may not present for treatment to a physician until symptoms persist for a significant period or they recur. On MRI, increased T2 signal is indicative of localized edema or a fluid collection and may indicate acuity in the appropriate clinical context. Concomitantly decreased $\mathrm{T} 1$ signal may represent increased hemosiderin deposition and indicate acute hemorrhage. However, in the context of the lumbar spine and the intervertebral disc, these features are difficult to distinguish and may not be truly indicative of acuity of symptoms. The goal of this study was to determine whether any MRI signal characteristics could predict the acuity of symptoms in patients being treated for a LDH.

The results of this study found significant differences between groups for only a few measurements. Rater 2 found a higher proportion of disc bulges and lower proportion of sequestrations in the chronic group $(P=.021)$ as well as a higher rate of abnormal T1 herniation signal in the acute group ( $P$ $=.048)$. Rater 1 found a significant difference in Pfirrmann grade with a higher grade in the chronic group $(P=.005)$ as well as higher prevalence of vertebral body spurring in the chronic group $(P=$
.007). However, no significant differences existed for most measurements in the study. Interobserver agreement ranged from moderate to substantial (0.4-0.8) for all measurements rated by both observers, except for T1 central signal, where interobserver reliability indicated no agreement, likely due to the very low number of abnormal ratings for both observers.

Few studies have been published in the literature examining MRI characteristics of LDH. Authors of existing studies have measured the size and location of the herniation as they relate to radiculopathy symptoms and need for operative intervention; however, none have attempted to measure signal characteristics to predict a temporal relationship with radiculopathy symptoms. ${ }^{11-14}$ Milette et $\mathrm{al}^{16}$ described a cohort of 45 patients with chronic low back pain, where MRI and discography were both performed, and 2 independent observers rated a total of 132 lumbar discs. The authors differentiated between central and peripheral signal characteristics on MRI as well as disc height, contour, and presence of nerve root compression. The authors found that, in this low back pain population, loss of disc height and abnormal signal intensity were predictive of annular tears extending beyond the outer annulus, and the presence of a disc bulge or protrusion was not necessarily indicative of symptoms. While we measured signal characteristics based on MRI, the patient population studied included patients with low back pain and not radiculopathy.

LDH is a common imaging feature in the degenerative lumbar spine. Many authors have 
shown the increased prevalence of degenerative MRI findings in asymptomatic individuals. ${ }^{3,5,20}$ Boden et $\mathrm{al}^{3}$ initially reported a $20 \%$ prevalence of $\mathrm{LDH}$ in patients less than 60 years old and a $36 \%$ prevalence of $\mathrm{LDH}$ patients that were over the age of 60 without a history of low back pain or radiculopathy. Similarly, in a prospective cohort study of asymptomatic patients randomly selected from the Veterans Affairs system, no significant associations existed between the presence of low back pain and disc height, desiccation, bulge, or protrusion; however, a significant association occurred with repetitive low back pain episodes and disc extrusion. ${ }^{5}$ In a systematic review, Kim et al $^{21}$ studied the diagnostic accuracy of MRI for LDH and found that, despite a pooled $80.9 \%$ sensitivity and $81 \%$ specificity, the existing evidence was low quality due to study design, inconsistency, and imprecision. Given that age can be a confounding factor, the presence of a $\mathrm{LDH}$ on imaging may not necessarily be the cause of the patient's symptoms. Furthermore, the results from the current study suggest that it is difficult to accurately predict the timing of disc herniation based solely on the signal characteristics.

LDHs have the unique ability to be resorbed with conservative treatment. Postulated mechanisms for disc resorption include dehydration of the disc, spontaneous retraction back into intervertebral disc space, or enzymatic degradation and phagocytosis in the inflammatory reaction. ${ }^{8}$ Disc hydration correlates with MRI T2 signal intensity; therefore, higher MRI T2 at the periphery of the disc herniation is thought to signal increased hydration with more potential to resorb or dehydrate, indirectly indicating acuity. ${ }^{8}$ Rim enhancement on gadolinium-enhanced MRIs may also indicate increased blood flow and an inflammatory reaction that may indicate an acutely herniated disc. Pathology specimens of these herniated discs show the presence of macrophages and matrix metalloproteinase-mediated enzymatic degradation ${ }^{22,23}$ As shown by Chiu et al, ${ }^{10}$ rates of spontaneous regression are significantly higher for disc extrusions and sequestionrations. The presence of these findings on MRI may indirectly suggest acuity of symptoms. Despite these findings, no studies have temporally correlated the onset of symptoms with these findings.

Several limitations exist in this study. It was a retrospective design, and patients self-reported the duration of symptoms at their first visit with the treating spine surgeon. It is possible that patients may have underreported or overreported the duration of their symptoms, subjecting this measure to recall bias. In addition, while certain disc characteristics measurements were measured independently by 2 different observers, repeated measurements were not conducted at different timepoints. Interobserver agreement was moderate to substantial for most measures; however, it was poor to fair for 2 measures ( $\mathrm{T} 1$ central signal and $\mathrm{T} 1$ herniation signal). Adding additional observers with more measurements would have enhanced the strength of this study.

\section{CONCLUSIONS}

We are the first, to our knowledge, to measure MRI signal characteristics and attempt to correlate these findings temporally with duration of symptoms. The findings in this study suggest that, while some characteristics of degeneration such as Pfirrmann grade or spurring may be indicative of chronicity, no clear imaging characteristics are suggestive of acuity. Due to the high prevalence of degenerative findings in the lumbar spine in even asymptomatic patients, careful clinical judgment is required to determine whether imaging findings are responsible for present symptoms.

\section{REFERENCES}

1. Jarvik JG, Deyo RA. Diagnostic evaluation of low back pain with emphasis on imaging. Ann Intern Med. 2002;137(7):586. doi:10.7326/0003-4819-137-7-20021001000010

2. Wassenaar M, Rijn RM van, Tulder $M W$ van, et al Magnetic resonance imaging for diagnosing lumbar spinal pathology in adult patients with low back pain or sciatica: a diagnostic systematic review. Eur Spine J. 2012;21(2):220. doi:10.1007/S00586-011-2019-8

3. Boden SD, Davis DO, Dina TS, Patronas NJ, Wiesel SW. Abnormal magnetic-resonance scans of the lumbar spine in asymptomatic subjects. A prospective investigation. $J$ Bone Joint Surg Am. 1990;72(3):403-408.

4. Jensen MC, Brant-Zawadzki MN, Obuchowski N, Modic MT, Malkasian D, Ross JS. Magnetic resonance imaging of the lumbar spine in people without back pain. $N$ Engl J Med. 1994;331(2):69-73. doi:10.1056/NEJM199407143310201

5. Jarvik JJ, Hollingworth W, Heagerty P, Haynor DR, Deyo RA. The Longitudinal Assessment of Imaging and Disability of the Back (LAIDBack) Study Baseline Data. Vol. 26; 2000. https://insights.ovid.com/crossref?an $=00007632$ 200105150-00014. Accessed December 6, 2018

6. Weber H. Lumbar disc herniation. A controlled, prospective study with ten years of observation. Spine (Phila 
Pa 1976). 1983;8(2):131-140. http://www.ncbi.nlm.nih.gov/ pubmed/6857385. Accessed May 15, 2019.

7. Weber H, Holme I, Amlie E. The natural course of acute sciatica with nerve root symptoms in a double-blind placebocontrolled trial evaluating the effect of piroxicam. Spine (Phila Pa 1976). 1993;18(11):1433-1438.

8. Yang X, Zhang Q, Hao X, Guo X, Wang L. Spontaneous regression of herniated lumbar discs: report of one illustrative case and review of the literature. Clin Neurol Neurosurg. 2016;143:86-89. doi:10.1016/j.clineuro.2016.02.020

9. Takada E, Takahashi M, Shimada K. Natural history of lumbar disc hernia with radicular leg pain: spontaneous MRI changes of the herniated mass and correlation with clinical outcome. J Orthop Surg. 2001;9(1):1-7.

10. Chiu C-C, Chuang T-Y, Chang K-H, Wu C-H, Lin P-W, Hsu W-Y. The probability of spontaneous regression of lumbar herniated disc: a systematic review. Clin Rehabil. 2015;29(2):184-195. doi:10.1177/0269215514540919

11. Carragee EJ, Kim DH. A prospective analysis of magnetic resonance imaging findings in patients with sciatica and lumbar disc herniation. Correlation of outcomes with disc fragment and canal morphology. Spine (Phila Pa 1976). 1997;22(14):1650-1660.

12. Karppinen J, Malmivaara A, Tervonen O, et al. Severity of symptoms and signs in relation to magnetic resonance imaging findings among sciatic patients. Spine (Phila Pa 1976). 2001;26(7):E149-E154. http://www.ncbi.nlm.nih.gov/pubmed/ 11295915. Accessed May 15, 2019.

13. Mysliwiec LW, Cholewicki J, Winkelpleck MD, Eis GP. MSU classification for herniated lumbar discs on MRI: toward developing objective criteria for surgical selection. Eur Spine J. 2010;19(7):1087-1093. doi:10.1007/s00586-009-1274-4

14. Carlisle E, Luna M, Tsou PM, Wang JC. Percent spinal canal compromise on MRI utilized for predicting the need for surgical treatment in single-level lumbar intervertebral disc herniation. Spine J. 2005;5(6):608-614. doi:10.1016/j.spinee. 2005.05.384

15. Jha SC, Higashino K, Sakai T, et al. Clinical significance of high-intensity zone for discogenic low back pain: a review. $J$ Med Investig. 2016;63(1.2):1-7. doi:10.2152/jmi.63.1

16. Milette PC, Fontaine S, Lepanto L, Cardinal E, Breton G. Differentiating lumbar disc protrusions, disc bulges, and discs with normal contour but abnormal signal intensity. Spine (Phila Pa 1976). 1999;24(1):44-53.

17. Pfirmann CWA, Metzdorf A, Zanetti M, Hodler J, Boos N. Magnetic Resonance Classification of Lumbar Intervertebral Disc Degeneration. Vol 26. https://insights-ovid-com. proxy 1.lib.tju.edu/pubmed?pmid=11568697. Accessed December 21, 2018.

18. Fleiss JL. Measuring nominal scale agreement among many raters. Psychol Bull. 1971;76(5):378-382.
19. Landis JR, Koch GG. The measurement of observer agreement for categorical data. Biometrics. 1977;33(1):159-174. http://www.ncbi.nlm.nih.gov/pubmed/843571. Accessed June $12,2019$.

20. Brinjikji W, Diehn FE, Jarvik JG, et al. MRI findings of disc degeneration are more prevalent in adults with low back pain than in asymptomatic controls: a systematic review and meta-analysis. AJNR Am J Neuroradiol. 2015;36(12):23942399. doi:10.3174/ajnr.A4498

21. Kim J-H, van Rijn RM, van Tulder MW, et al. Diagnostic accuracy of diagnostic imaging for lumbar disc herniation in adults with low back pain or sciatica is unknown; a systematic review. Chiropr Man Therap. 2018;26:37. doi:10. 1186/s12998-018-0207-x

22. Kato T, Haro H, Komori H, Shinomiya K. Sequential dynamics of inflammatory cytokine, angiogenesis inducing factor and matrix degrading enzymes during spontaneous resorption of the herniated disc. J Orthop Res. 2004;22(4):895-900. doi:10.1016/j.orthres.2003.11.008

23. Doita M, Kanatani T, Ozaki T, Matsui N, Kurosaka M, Yoshiya S. Influence of macrophage infiltration of herniated disc tissue on the production of matrix metalloproteinases leading to disc resorption. Spine (Phila Pa 1976). 2001;26(14):1522-1527. http://www.ncbi.nlm.nih.gov/pubmed/ 11462080. Accessed May 15, 2019.

Disclosures and COI: The authors, their immediate family, and any research foundation with which they are affiliated did not receive any financial payments or other benefits from any commercial entity related to the subject of this article. There are no relevant disclosures.

Corresponding Author: Dhruv K.C. Goyal, MD, Department of Orthopaedic Surgery, Rothman Institute, Thomas Jefferson University, 925 Chestnut Street, 5th Floor, Philadelphia, PA 19107. Phone: (937) 830-7110; Email: dhruvkcgoyal@ gmail.com.

Published 1 June 2021

This manuscript is generously published free of charge by ISASS, the International Society for the Advancement of Spine Surgery. Copyright (C) 2021 ISASS. To see more or order reprints or permissions, see http://ijssurgery.com. 